\title{
GOOGLE SLIDE DAN QUIZIZZ DALAM PENGEMBANGAN BUKU AJAR ELEKTRONIK INTERAKTIF (BAEI) MATEMATIKA
}

\author{
Arum Oktaliana Sari ${ }^{a}$, Guntur Cahaya Kesuma ${ }^{b}$, Dian Anggrainic

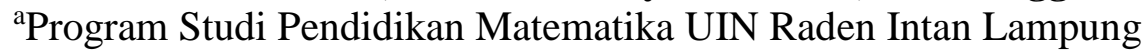 \\ Jl. Letkol H. Endro Suratmin Sukarame Bandar Lampung Telp. (0721)703260 \\ arumoktaliana77@gmail.com \\ bProgram Studi Pendidikan Bahasa Arab UIN Raden Intan Lampung \\ Jl. Letkol H. Endro Suratmin Sukarame Bandar Lampung Telp. (0721)703260 \\ gunturck69@gmail.com \\ ${ }^{\mathrm{c}}$ Program Studi Sains Aktuaria ITERA Lampung Selatan \\ Jl. Terusan Ryacudu Way Hui Jati Agung Lampung Selatan Telp. (0721)8030188 \\ dian.anggraini@at.itera.ac.id
}

\begin{abstract}
ABSTRAK
Penelitian ini bertujuan untuk mengetahui kemenarikan dan kelayakan serta keefektifan pembelajaran yang diterapkan dengan menggunakan buku ajar elektronik interaktif (BAEI) berbantuan google slide dan quizizz pada materi matriks. Metode penelitian ini adalah penelitian dan pengembangan (R\&D) dengan model pengembangan Borg and Gall. Ada 10 tahap dalam pengembangan ini yaitu 1) Potensi dan masalah, 2) Pengumpulan data, 3) Desain produk, 4) Validasi desain, 5) Revisi desain, 6) Uji coba produk, 7) Revisi produk, 8) Uji coba pemakaian. 9) Revisi produk, 10) Produksi masal. Instrumen pengumpulan data yang digunakan adalah angket yang diberikan kepada ahli materi dan ahli media untuk mengetahui kelayakan produk, dan diberikan kepada peserta didik untuk mengetahui kemenarikan produk yang telah dikembangkan serta instrument tes pretest dan posttest. Hasil analisis data yang diperoleh dari ahli materi dan ahli media dinyatakan bahwa bahan ajar yang dikembangkan layak untuk digunakan dengan memperoleh kriteria "Valid" dengan nilai rata- rata ahli materi sebesar 3,76 dan ahli media sebesar 3,48. Kemudian respon peserta didik terhadap buku ajar elektronik (BAEI) pada uji coba kelompok kecil dan uji coba kelompok besar (lapangan) memperoleh kriteria "Sangat Menarik" dengan hasil rata- rata skor pada uji coba kelompok kecil yaitu 3,28 dan hasil rata- rata skor kelompok besar (lapangan) yaitu 3,49. Hasil analisis uji keefektifan dengan menggunakan effect size pada pretest dan posttest memperoleh rata- rata skor 0,72 dan termasuk dalam kategori sedang.
\end{abstract}

Kata Kunci: BAEI, Google Slide, Quizizz

\section{GOOGLE SLIDE AND QUIZIZZ IN THE DEVELOPMENT OF INTERACTIVE ELECTRONICS BOOK (BAEI) MATHEMATICS}

\begin{abstract}
This study aims to determine the attractiveness and feasibility and effectiveness of learning implemented using interactive electronic textbooks (BAEI) assisted by Google slides and quizizz on the matrix material. This research method is research and development (R\&D) with the Borg and Gall development model. There are 10 stages in this development namely 1) Potential and problems, 2) Data collection, 3) Product design, 4) Design validation, 5) Design revision, 6) Product trial, 7) Product revision, 8) Trial usage. 9) Product revision, 10) Mass production. Data collection instruments used were questionnaires given to material experts and media experts to determine product viability, and were given to students to find out the attractiveness of products that had been developed as well as pretest and posttest test instruments. The results of data analysis obtained from material experts and media experts stated that teaching materials developed were feasible to be used by obtaining "Valid" criteria with an average score of material experts of 3.76 and media experts of 3.48. Then the students' response to the electronic textbook (BAEI) in small
\end{abstract}


group trials and large group trials (field) obtained the criteria of "Very Attractive" with the average score on the small group trial of 3.28 and the average results the score of large groups (field) is 3.49. The results of the effectiveness test analysis using effect sizes on the pretest and posttest obtained an average score of 0.72 and included in the medium category.

Keywords: BAEI, Google Slide, Quizizz

\section{Pendahuluan}

Bahan ajar merupakan salah satu hal penting dalam proses pembelajaran yang menentukan kegiatan-kegiatan pembelajaran dan keberhasilan tercapai tujuan pembelajaran. National Centre for Competency Based Training menjelaskan bahan ajar adalah segala bentuk bahan yang digunakan untuk membantu guru atau instruktur dalam melaksanakan proses pembelajaran dikelas (Praswoto, 2011:16).

Selanjutnya,Aunurrahman(2010:199)

menyatakan bahwa selama proses belajar berlangsung, masalah belajar seringkali berkenaan dengan bahan ajar (materi) dan sumber belajar. Sumber belajar yang praktis dan sederhana, yang tidak memerlukan peralatan dan perawatan khusus tidak sulit dicari, tidak mahal harganya, dan tidak memerlukan tenaga terampil yang khusus, adalah sumber yang harus mendapatkan prioritas utama dan pertama (Dimyati dan Mudjiono, 2010).

$\begin{array}{ccc}\text { Hasil } & \text { wawancara } & \text { yang } \\ \text { dilakukan oleh peneliti kepada } & \text { guru }\end{array}$ di SMAN 2 Pringsewu dan MAN 1 Pringsewu tentang bahan ajar diperoleh bahwa dalam proses pembelajaran matematika bahan ajar yang digunakan belum pernah menggunakan buku ajar elektronik interaktif tetapi masih berupa buku yang diedarkan dari dinas pendidikan. Selain melakukan wawancara terhadap guru, penulis melakukan penyebaran angket kepada peserta didik yang terdiri dari tiga pertanyaan, menyatakan bahwa peserta didik masih merasa kesulitan dalam mempelajari matematika, sekitar $55 \%$ siswa mengalami kesulitan dalam memahami materi matematika. Minat siswa pada upaya penggunaan buku ajar elektronik sebesar 49\%. Keinginan untuk pengembangan buku ajar elektronik khususnya pada materi matriks sebesar $46 \%$. Peserta didik sangat tertarik untuk dikembangkannya sebuah buku ajar elektronik interaktif (BAEI) sebagai bahan pembelajaran mereka. Tidak hanya wawancara dan angket yang menjadikan acuan pada penelitian ini. Peneliti memperoleh 
sumber referensi dari penelitian terlebih dahulu, menurut (Rikma Fitrialeni Darlen, Sjarkawi, dan Aprizal Lukman, 2015) menunjukkan bahwa dengan menggunakan media pembelajaran berbasis multimedia interaktif pada saat pembelajaran dapat meningkatkan motivasi belajar. Menurut Mahas Amri(2018) pembelajaran menggunakan bahan ajar elektronik menghasilkan tingkat prestasi peserta didik pada pembelajaran matematika yang lebih baik dibanding dengan pembelajaran konvensional. Menurut (Artisa Indariani, Nur Ayni, Surya Amami Pramuditya, dan Muchamad Subali Noto, 2018) menunjukkan pembelajaran menggunakan bahan ajar digital berpotensi untuk membuat peserta didik agar lebih mandiri dalam belajar matematika. Menurut (Isna Rafianti, Yani Setiani, dan Indhira Asih Vivi Yandari, 2018) dalam penelitiannya mengungkapkan bahan ajar interaktif sangat baik untuk digunakan dalam pembelajaran matematika.

Kesimpulan dari beberapa penelitian tersebut adalah penggunaan bahan ajar elektronik interaktif dalam proses pembelajaran sangat baik yang dapat memberikan peningkatan prestasi dan menjadikan peserta didik lebih mandiri. Namun dari beberapa penelitian terdahulu bahan ajar interaktif yang digunakan hanya berupa text book dan dikembangan dengan software adobe flash dan Geogebra. Dalam penelitian ini peneliti memberikan keterbaharuan terhadap bahan ajar elektronik interaktif tidak hanya berbentuk text book saja akan tetapi dilengkapi pula dengan teks, animasi, suara, video dan soal- soal yang semuanya dikemas dalam bentuk visualisasi animasi yang dilengkapi dengan warna, suara dan musik. Peneliti menggunakan aplikasi Google Slide dan Quizizz. Google Slide merupakan satu dari banyaknya aplikasi yang dimiliki oleh Google. Google Slide adalah aplikasi persentasi online dengan menggunakan google slide kita juga dapat membuat, menyimpan dan membagi dokumen dengan pengguna lainnya. Penggunaan buku ajar dengan aplikasi google slide mencegah pengguna untuk kerusakan atau kehilangan buku ajar yang dimiliki. Sedangkan Quizizz merupakan aplikasi online dimana kuis berupa soal- soal tes dapat dikembangkan atau disajikan dalam bentuk permainan. Dengan aplikasi Google Slide ini penulis akan 
membuat buku ajar elektronik interaktif dan menghubungkannya dengan Quizizz.

Metode Penelitian

Penelitian ini merupakan penelitian pengembangan (Research and Development). Penelitian pengembangan ini menggunakan model Borg and Gall yang diadaptasi oleh Sugiono yaitu: 1) Potensi dan Masalah, 2) Pengumpulan Data, 3) Desain Produk, 4) Validasi Desain, 5) Revisi Desain, 6) Ujicoba Produk, 7) Revisi Produk, 8) Ujicoba Produk, 9) Revisi Produk, 10) Produksi Masal. Teknik pengumpulan data yang digunakan penulis adalah wawancara, penyebaran angket dan tes. Angket yang digunakan adalah angket validasi kepada para pakar ahli dan angket peserta didik. Adapun data kualitatif dihasilkan dari saran dan masukan para pakar ahli sedangkan data kuantitatif dihasilkan dari hasil validasi dan tes yang telah dilakukan. Teknik pengolahan data yang digunakan dalam pengolahan data hasil tes adalah teknik uji effect size. Tabel yang digunakan untuk menkonversikan data hasil angket dapat dilihat pada Tabel 1 (Ana Kurnia Sari, Chandra Ertikanto, dan Wayan Suana, 2015).
Tabel 1. Skor kriteria angket

\begin{tabular}{|c|c|c|}
\hline Skor & $\begin{array}{l}\text { Konversi } \\
\text { validasi } \\
\text { ahli }\end{array}$ & $\begin{array}{l}\text { Konversi } \\
\text { peserta } \\
\text { didik }\end{array}$ \\
\hline $\begin{array}{l}3,25<\bar{x} \\
\leq 4,00\end{array}$ & Valid & $\begin{array}{l}\text { Sangat } \\
\text { Menarik }\end{array}$ \\
\hline $\begin{array}{l}2,5<\bar{x} \\
\leq 3,25\end{array}$ & $\begin{array}{l}\text { Cukup } \\
\text { Valid }\end{array}$ & Menarik \\
\hline $\begin{array}{l}1,75<\bar{x} \\
\leq 2,5\end{array}$ & $\begin{array}{l}\text { Kurang } \\
\text { Valid }\end{array}$ & $\begin{array}{l}\text { Kuranga } \\
\text { Menarik }\end{array}$ \\
\hline $\begin{array}{l}1,00<\bar{x} \\
\leq 1,75\end{array}$ & Tidak Valid & $\begin{array}{l}\text { Sangat } \\
\text { tidak } \\
\text { Menarik }\end{array}$ \\
\hline
\end{tabular}

Hasil dan Pembahasan

Penelitian dan pengembangan dalam penelitian ini menghasilkan produk buku ajar elektronik interaktif dengan menggunakan aplikasi google slide dan quizizz. Pengembangan buku ajar elektronik interaktif terdiri dari dua bagian utama yaitu materi dan evaluasi interaktif. Materi yang disajikan terdiri atas 2 materi pokok yaitu Operasi pada Matriks dan Determinan dan Invers Matriks. Penyajian materi pada buku ajar terdapat beberapa video sebagai informasi tambahan bagi peserta didik yang berkaitan dengan materi matriks. Buku ajar ini juga dilengkapi dengan soal evaluasi interaktif di setiap bab pada buku yang dikemas menggunakan aplikasi Quizizz. Langkah pertama yang dilakukan oleh peneliti yaitu menggali potensi dan masalah dengan melakukan wawancara 
kepada guru di SMAN 2 Pringsewu dan MAN 1 Pringsewu supaya dapat mengetahui potensi yang ada di sekolah dan masalah yang dapat dijadikan potensi. Berdasarkan hasil wawancara pada guru dari SMAN 2 Pringsewu dan MAN 1 Bandar Lampung diperoleh informasi bahwa bahan ajar disekolah masih berupa buku cetak dan belum pernah terlaksana pembelajaran menggunakan bahan ajar elektronik. Hasil penyebaran angket pada saat pra penelitian kepada peserta didik diketahui bahwa peserta didik masih mengalami kesulitan dalam mempelajari matematika. Menurut Prastowo (2015) mutu pembelajaran menjadi rendah ketika guru hanya terpaku pada bahan-bahan ajar yang konvensional tanpa ada kreativitas untuk mengembangkan bahan ajar tersebut secara inovatif. Peserta didik juga sangat berantusias jika dilakukan pengembangan buku ajar berbentuk digital atau elektronik.

Setelah potensi dan masalah diperoleh, langkah kedua yaitu mengumpulkan data. Pada langkah ini peneliti menganalisis silabus dan rencana pelaksanaan pembelajaran (RPP) kemudian mengumpulkan referensi buku beserta sumbersumber lain yang akan digunakan dalam penyusunan buku ajar elektronik interaktif.

$$
\text { Langkah ketiga yang }
$$
dilaksanakan setelah mendapatkan permasalahan awal yang menjadikan acuan dalam pengembangan ini adalah mendesain produk. Penyusunan buku ajar elektronik interaktif dilaksanakan dengan merumuskan kompetensi dasar dan indikator dan setelahnya menyusun materi yang akan dicantumkan dalam buku ajar elektronik interaktif, gambar-gambar, video pembelajaran serta sumber lainnya. Langkah keempat sesudah buku ajar dibuat adalah validasi. Validasi dilaksanakan dengan 3 orang ahli materi dan 3 orang ahli media. Hasil dari validasi materi menunjukkan hasil yang dicapai pada aspek kelayakan isi sebesar 3,69 dengan kriteria "Valid" dan aspek kelayakan penyajian sebesar 3,83 dengan kriteria "Valid". Hasil validasi media pada aspek kelayakan kegrafikan mendapatkan nilai sebesar 3,48 dengan kriteria "Valid".

Berdasarkan hasil validasi diperoleh skor rata-rata pada kriteria valid. Namun, sebelum mendapatkan hasil valid peneliti melakukan revisi terhadap produk yang dikembangkan berdasarkan saran dan masukan- 
masukan dari para ahli validasi materi dan validasi media. Beberapa perbaikan dilakukan diantaranya sebagai berikut.

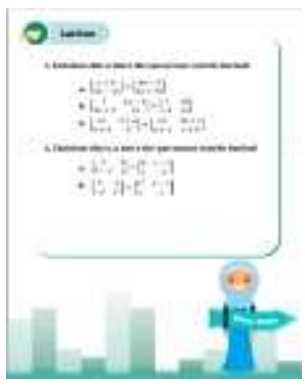

Gambar 2.

Sebelum

perbaikan

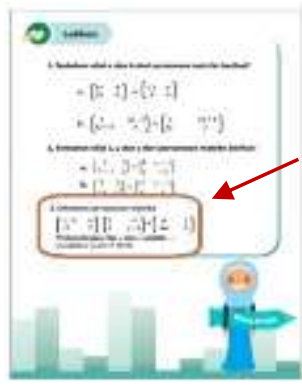

Gambar 3.

Setelah perbaikan
Produk yang sudah selesai direvisi dan dinyatakan layak untuk uji coba maka dilanjutkan ketahap uji coba kelompok kecil dan uji coba kelompok besar (lapangan). Seperti yang telah dijelaskan Sari, Farida, \& Putra(2017) media pembelajaran yang telah dikembangkan tidak hanya cukup dengan kelayakan media saja, tetapi juga kemenarikan oleh peserta didik. Uji coba kelompok kecil dilakukan kepada 9 murid di SMAN 2 Pringsewu dengan perolehan hasil 3,44 dengan kriteria "Sangat Menarik". Uji coba kelompok kecil yang dilakukan di MAN 1 Pringsewu dilaksanakan dengan 15 peserta didik dan memperoleh skor sebesar 3,42 dengan kriteria "Sangat Menarik". Uji coba kelompok kecil yang dilakukan di dua sekolah menunjukkan kriteria hasil yang sangat menarik dimana dengan kriteria ini kita dapat langsung melakukan uji coba kelompok besar (lapangan). Uji coba kelompok besar (lapangan) melibatkan 27 peserta didik di SMAN 2 Pringsewu dengan perolehan skor sebesar 3,25 dengan kriteria "Sangat Menarik" dan 34 peserta didik di MAN 1 Pringsewu dengan perolehan skor sebesar 3,25 dengan kriteria "Sangat Menarik".

Setelah melakukan uji coba produk langkah kelima yang di tempuh adalah revisi produk. Karena buku ajar yang dikembangkan sudah dalam kategori sangat menarik, maka dapat disimpulkan bahwa buku ajar tersebut telah selesai dikembangkan dan akan menghasilkan produk akhir. Sesudah produk selesai diperbaiki berdasarkan saran selanjutnya peneliti melakukan uji coba produk untuk mengukur efektifitas produk buku ajar elektronik interaktif yang digunakan peserta didik selama pembelajaran matriks. Peneliti menggunakan effect size dalam memperhitungkan tingkat keefektifan penggunaan produk. Uji efektifitas ini dilakukan pada peserta didik kelas XI SMAN 2 Pringsewu dan MAN 1 Pringsewu. 
Berdasarkan perhitungan data menggunakan effect size diperoleh untuk SMAN 2 Pringsewu $E_{s}=0,87$ dengan kriteria "tinggi" sedangkan hasil yang di peroleh di MAN 1 Pringsewu $E_{s}=0,57$ dengan kriteria sedang. Hasil dari kedua sekolah jika digabungkan memperoleh skor $E_{s}=$ 0,72 dengan kriteria "sedang" yang berarti penggunaan buku ajar elektronik interaktif (BAEI) berbantuan google slide dan quizizz. pada materi matriks cukup efektif dengan klasifikasi tergolong sedang. Dari kesimpulan tersebut menunjukkan bahwa bahan ajar elektronik interaktif (BAEI) berbantuan google slide dan quizizz dapat meningkatkan kemampuan hasil belajar siswa. Penelitian ini menciptakan bahan ajar elektronik interaktif (BAEI) berbantuan google slide dan quizizz, pendidik sebagai pengajar mampu menciptakan pembelajaran aktif, kreatif dan inovatif, karena tidak dapat dipungkiri, tujuan pembelajaran yang sesungguhnya adalah menggunakan bahan ajar yang tepat dan bervariasi dalam proses pembelajaran sehingga dapat mengurangi sikap pasif peserta didik.

\section{Kesimpulan}

Kesimpulan yang diperoleh dari hasil penelitian dan pengembangan ini menghasilkan bahan ajar elektronik interaktif (BAEI) berbantuan google slide dan quizizz. Berdasarkan hasil angket validasi diperolah rata-rata 3,76 oleh ahli materi, dan 3,48 oleh ahli media dengan kriteria sangat menarik. Sedangkan hasil uji coba respon siswa diperoleh skor rata-rata 3,34 dengan kriteria sangak menarik. Ditinjau dari hasil uji effect size diperoleh rata-rata 0,72 pada kategori sedang.

\section{Daftar Pustaka}

Amri, Mahas, (2018). Pengembangan Bahan Ajar Elektronik Berbasis Geogebra Dengan Model Penemuan Terbimbing Pada Materi Bilangan Bulat: Unnes Science Education Journal, 1, 792-95.

Aunurrahman. (2010). Belajar dan pembelajaran. Bandung: Penerbit Alfabeta.

Darlen, Rikma Fitrialeni, Sjarkawi, and Aprizal Lukman, (2015). Pengembangan E-Book Interaktif Untuk Pembelajaran Fisika SMP: Jurnal TeknoPedagogi, 5(1), 13-23.

Dimyati dan Mudjiono. (2010). Belajar dan Pembelajaran. Jakarta: RINEKA CIPTA

Indariani, Artisa, Nur Ayni, and Surya Amami Pramuditya, (2019). Teknologi Buku Digital Matematika Dan Penerapan Potensialnya Dalam Distance Learning: Jurnal Nasional 
Pendidikan Matematika, 3(1), 112.

Praswoto, A. (2011). Panduan Kreatif Membuat Bahan Ajar Inovatif. Yogyakarta: Pusat Diva Press.

Rafianti, Isna, Yani Setiani, and Indhira Asih Vivi Yandari, (2018). Pengembangan Bahan Ajar Interaktif Tutorial Dalam Pembelajaran Matematika Siswa SMP: Jurnal Penelitian Dan Pembelajaran Matematika, 11(2).

Sari, A. U., Farida, F., \& Putra, F. G. (2017). Pengembangan Media Pembelajaran Berbantuan Web Dengan Pendekatan
Etnomatematika Pada Pokok

Bahasan BANGUN Ruang Sisi Datar. Prosiding Seminar Nasional Matematika dan Pendidikan Matematika, 1(1), 209-214.

Sari, Ana Kurnia, Chandra Ertikanto, Dan Wayan Suana. "Pengembangan Lks Memanfaatkan Laboratorium Virtual Pada Materi Optik Fisis Dengan Pendekatan Saintifik." Jurnal Pembelajaran Fisika 3, No. 2 (7 April 2015). 